\title{
PROPHYLACTICS
}

IN CHABOA OF

MARY M. RIDDLE

\section{PRACTICAL HOME MODIFICATION OF COW'S MILK}

\section{BY MARY STEELE EWING}

Apothecary at the Boston City Hospital, South Department

Durivg the last decade a great deal has been written regarding modified milk as a substitute feeding for infants.

In many of the larger cities laboratories have been established where milk is modified on a large scale, and in consequence great strides have becn taken towards reducing the death-rate of nursing infants.

Later the question arose, "What can be done for the less fortunate infants, who, owing to the expense or to excessive distances, are unable to profit by the city laboratory?"'

Soon numerous articles were publishcd in both medical and nursing journals detailing methods for producing at home as nearly as possible as chemically correct a product as could be obtained from the laboratory.

Many of their articles have been extremely scientific, those written by physicians dealing largely with what combinations agree with infants of specified ages; those by chemists, of analytical and synthetical results obtained under certain conditions; but there is still a demand for a clear and concise working process, such that anyone who is not a chemist, but a person of good average intelligence with a minimum of time to expend, could pursue and obtain satisfactory results.

The following is a process which many nurses have adopted to their satisfaction.

We should first be sure of the absence of tuberculosis in the herd from which the milk is obtained. We should use the milk of the "mixed herd." By the term "mixed herd" we refer to the fact of the individual cows having calved at different periods, thus making the milk of no particular age from time of calving.

All authorities agree in preferring milk of the domestic herds, as Durham, Holstein, Ayrshire, to the fancier stock, as Jersey or Guernsey, since they are hardier, have greater constitutional vigor, are 
not so nervous, and consequently there is less liability to sudden fluctuation in the percentage of fat and proteids.

We designate our milk as Whole Milk.-Milk before any cream has been removed.

Top Milk.-The top one-fourth of the whole milk after the fat has been allowed to separate.

Milk.-The bottom three-fourths of the milk set, which contains practically no fat.

The milk, as soon as possible after leaving the cow, should be strained and a sufficient amount collected in a wide-mouthed glass bottle or a clean tin can, so that the top one-fourth will at least equal the amount of "top milk" called for in the recipe. A quart will usually be the right amount to collect, and a quart Mason jar is a convenient receptacle.

The jar should be set in ice-water, a clean cloth thrown over it, and left for about fifteen minutes to dispose of the animal heat. The jar should then be sealed and allowed to stand in ice-water for six hours, when it is ready for use. At the end of this time there will be discerned an easily perceptible line of demarcation between the milk and cream. The top one-fourth should then be decanted from the bottom three-fourths into a graduate. If the bottle be inclined slowly, all the fat can readily be poured off in the top eight ounces, leaving milk alone in the bottom twenty-four. This "top milk" should be well mixed.

In round numbers good cow's milk taken from a mixed herd will assay:

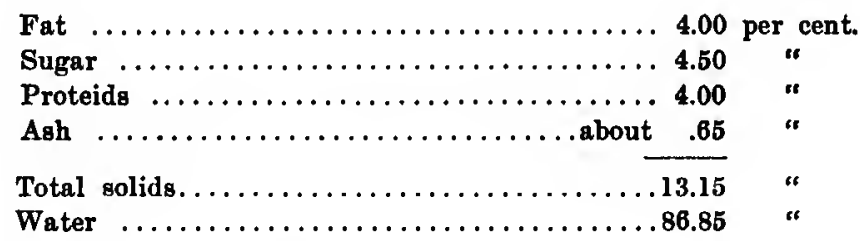

Normal human milk will assay about:

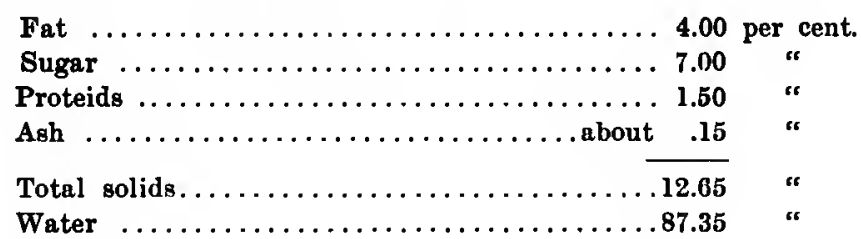

It will be seen that the percentage of fat present in cow's milk and human milk is the same; that the sugar in human milk is increased 
by two and one-half per cent., and that the proteids are diminished two and one-half per cent.

Milk which has just left the udder is neutral, but on standing it soon becomes acid, so we add five per cent. lime-water in each instance to each recipe, unless more or less is called for by the physician.

Since it is easier to calculate with a multiple of ten, we will make up twenty ounces, as this is an amount often called for, and increase or diminish it fractionally according to the amount ordered in the prescription.

We must have on hand:

1. "Top milk," which is the top one-fourth of the milk set, and should assay ten per cent. fat.

2. Recently boiled water.

3. Lime-water.

4. "Milk," being the bottom three-fourths, after the top one-fourth has been decanted.

5. Milk-sugar.

It is evident that if we use cream containing ten per cent. fat, each ounce of cream in a twenty-ounce mixture will give to the entire mixture one-half per cent. fat, for one-twentieth of ten per cent. is one-half per cent.

In the same way we calculate the proteids; one-twentieth of four per cent., which would be two-tenths per cent. proteids, in one ounce of milk and cream, or it would take five ounces of milk and cream together to obtain one per cent. proteids.

In calculating the sugar we must allow for the four per cent. already in the milk and cream. For example, if we have normal cow's milk, which assays,-

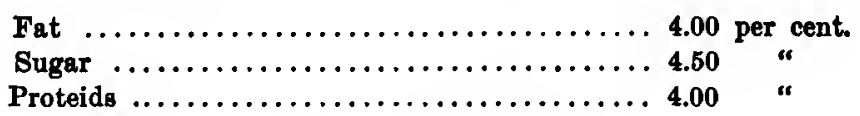

and wish to make a twenty-ounce mixture corresponding to normal human milk, which assays,-

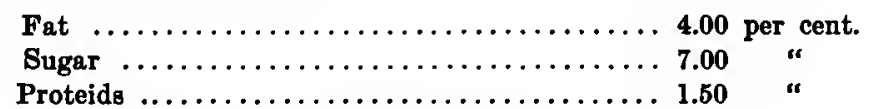

since there is one-half per cent. fat in each ounce of top milk, we will require,-

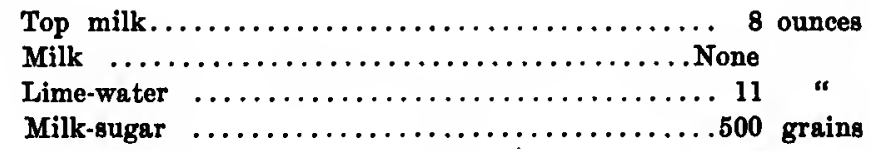


As the 1.5 per cent. proteids will be in the eight ounces of top milk used, this recipe will require no extra milk.

The sugar will be calculated in this way. We already have eight ounces top milk, which, as cow's milk assays 4.5 per cent. sugar, will contain one hundred and seventy-two grains; we want seven per cent., or six hundred and seventy-two grains, then we will add the difference, which will be five hundred grains.

The milk-sugar should be rubbed up with the milk, as it is more soluble in milk than in water.

Another example to make

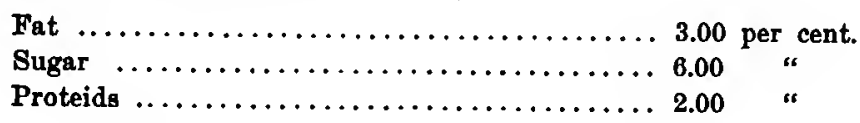

On the twenty-ounce basis—eight feedings of four ounces-this will require,-

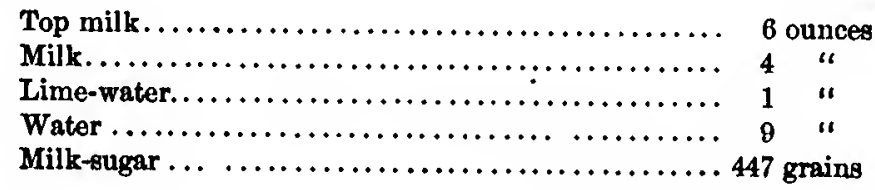

For thirty-two ounces we will use thirty-two twentieths, or eightfifths, of this amount, which will be,-

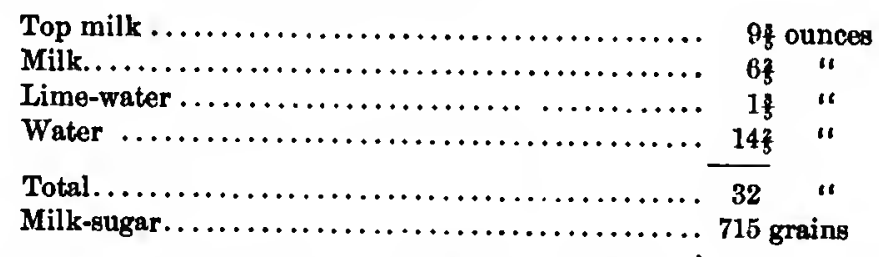

Sufficient milk for each feeding should be put in separate bottles, and the bottles stoppled with non-absorbent cotton.

The bottles should be placed in a water-bath, temperature $75^{\circ} \mathrm{C}$. $\left(167^{\circ} \mathrm{F}.\right)$, and allowed to remain during twenty-five minutes. At the expiration of this time they should be removed from the bath, drained, and set in the ice-chest. The milk is now ready for use.

The milk should not be raised to a much higher temperature than $75^{\circ} \mathrm{C}$., as the lime will be precipitated. It has been claimed that the temperature should not be carried as high as $75^{\circ}$, as lact-albumin coagulates at this temperature. This statement is correct, but the amount of lact-albumin present in this amount of milk is so small that the loss of it in assimilation is of minor consideration in com- 
parison with the tremendous good which may be accomplished through the destruction of the great number of bacterial organisms which will not survive in this temperature.

The object of placing the bottles in the ice-chest immediately after sterilizing is to prevent any spores which may be present from germinating, as they would if the milk were kept at room temperature or were not quickly cooled.

The bottles are stoppled with non-absorbent cotton, first, to keep out the bacteria and dust, and, second, in order that the air may circulate freely through the milk.

If the bottle in which the milk has been sterilized is used as a feeding-bottle and the nipple placed directly over its neck, the chances of contamination through outside agencies will be lessened.

As to the formation of the prescription, that, of course, should be formulated by the physician and is from his stand-point; however, it may be said that the percentage of fat, sugar, proteids, and amount should be regulated rather by the weight of the child than by its age.

It is customary to start with a very low percentage of fats and proteids and increase these proportions every few days until a formula has been obtained which will correspond to the child's age and improved condition.

\section{RATTLESNAKE POISON AS A CURE FOR LEPROSY}

Dr. Adoupho Mrrcondes de Moura, of Säo Paulo, Brazil, contributes a paper on the application of rattlesnake poison to the cure of leprosy to the German Medical Weekly Journal. This poison has been used for a long period by the natives for the treatment of skin diseases and even leprosy. Many wonderful cures of lepers through rattlesnake bites having been reported to him, Dr. de Moura set himself to make investigations. He experimented with the poison on fifteen lepers, and he has come to the conclusion that the lepra tuberculosa, if not complicated with another disease, is curable by its means. Professor Lewin, of Berlin, discusses the subject in the same number of the Weekly Journal. While he contends that the rattlesnake poison is not a true antidote, nevertheless he admits that it may have a temporary effect on the disease, and considers the matter worthy of investigation. 